\title{
Treatment of Uncomplicated Hypertension: Are ACE Inhibitors and Calcium Channel Blockers as Effective as Diuretics and $\beta$-Blockers?
}

\author{
Joseph J. Saseen, PharmD, Eric J. MacLaughlin, PharmD, and \\ John M. Westfall, MD, MPH
}

Editors' Note: This month we continue the feature STEPped Care: An Evidence-Based Approach to Drug Therapy. These articles are designed to provide concise answers to the drug therapy questions that family physicians encounter in their daily practice. The format of the feature will follow the mnemonic STEP: safety (an analysis of adverse effects that patients and providers care about), tolerability (pooled dropout rates from large clinical trials), effectiveness (bow well the drugs work and in what patient population[s]), and price (costs of drug, but also cost effectiveness of therapy). ${ }^{1}$ Hence, the name STEPped Care.

Since the informatics pioneers at McMaster University introduced evidence-based medicine, ${ }^{2}$ Slawson and colleagues ${ }^{3,4}$ bave brought it to mainstream family medicine education and practice. This feature is designed to further the mission of searching for the truth in medical practice. Authors will provide information in a structured format that allows the readers to get to the meat of a therapeutic issue in a way that can belp physicians (and patients) make informed decisions. The articles will discourage the use of disease-oriented evidence (DOE) to make treatment decisions. Examples of DOEs include blood pressure lowering, decreases in bemoglobin $A_{1 c}$, and so on. We will include studies that are POEMs - patientoriented evidence that matters (myocardial infarctions, pain, strokes, mortality, etc) - with the goal of offering our patients the most practical, appropriate, and scientifically substantiated therapies. Number needed to treat to observe benefit in a single patient will also be included as a way of defining advantages in terms that are relatively easy to understand. ${ }^{5,6}$

At times this effort will be frustrating. Even as vast as the biomedical literature is, it does not always support what clinicians do. We will avoid making conclusions that are not supported by POEMs. Nevertheless, POEMs should be incor- porated into clinical practice. The rest is up to the reader. Blending POEMs with rational thought, clinical experience, and importantly, patient preferences can be the essence of the art of medicine.

We bope you will find these new articles useful and easy to read. Your comments and suggestions are welcome. You may contact the editors through the editorial office of $7 A B F P$. We bope the articles provide you with useful information that can be applied in everyday practice, and we look forward to your feedback.

Bruce R. Canaday, PharmD

Keith Campagna, PharmD STEPped Care Feature Editors Fohn P. Geyman, MD, Editor Journal of the American Board of Family Practice

\section{References}

1. Shaughnessy AF, Slawson DC, Bennett JH. Separating the wheat from the chaff: identifying fallacies in pharmaceutical promotion. J Gen Intern Med 1994;9:563-8.

2. Evidence-based medicine: a new approach to teaching the practice of medicine. Evidence-Based Medicine Working Group. JAMA 1992;268:2420-5.

3. Slawson DC, Shaughnessy AF, Bennett JH. Becoming a medical information master: feeling good about not knowing everything. J Fam Pract 1994;38:505-13.

4. Shaughnessy AF, Slawson DC, Bennett JH. Becoming an information master: a guidebook to the medical information jungle. J Fam Pract 1994;39:489-99.

5. Laupacis A, Sackett D, Roberts RS. An assessment of clinically useful measures of the consequences of treatment. N Engl J Med 1988;318:1728-33.

6. Wiffen PJ, Moore RA. Demonstrating effectiveness - the concept of numbers-needed-to-treat. J Clin Pharm Ther $1996 ; 21: 23-7$.
Submitted, revised, 23 June 2002.

From the Department of Clinical Pharmacy (JJS), and Department of Family Medicine (JJS, JMW), University of Colorado Health Sciences Center, Denver, and the School of Pharmacy (EJM), Texas Tech University Health Sciences Center, Amarillo. Requests for reprints should be addressed to Joseph J. Saseen, PharmD, University of Colorado School of Pharmacy, 4200 E. 9th Ave. Box C238, Denver, CO 80262.
It is estimated that approximately $25 \%$ of the adult American population (ie, 50 million Americans) have hypertension. ${ }^{1,2}$ The Sixth Report of the Joint National Committee on Detection, Evaluation, and Treatment of High Blood Pressure (JNC VI) has been designed to help clinicians manage this disease. ${ }^{1}$ These treatment guidelines, consistent 
with the previous JNC V report from $1993,{ }^{3}$ recommend diuretics and $\beta$-blockers as first-line therapy for uncomplicated hypertension. This recommendation was based on landmark placebocontrolled clinical trials data that showed reduced morbidity and mortality with the use of these two drug classes. ${ }^{4-6}$

Angiotensin-converting enzyme (ACE) inhibitors and calcium channel blockers are recommended by the JNC VI as alternatives to diuretics and $\beta$-blockers unless compelling indications for their first-line use are present. ${ }^{1}$ ACE inhibitors are recommended as first-line agents for patients who have type 1 diabetes mellitus with proteinuria, heart failure, or previous myocardial infarction with systolic dysfunction and long-acting dihydropyridine calcium channel blockers may be used as a first-line agent in those with isolated systolic hypertension. Despite these recommendations, ACE inhibitors and calcium channel blockers (including dihydropyridine and agents other than dihydropyridine) are consistently the most frequently prescribed antihypertensive agents in both younger and older patients with hypertension. ${ }^{7,8}$

The definitive isolated effects of ACE inhibitors and calcium channel blockers on morbidity and mortality in the treatment of uncomplicated hypertension are unknown because there are no placebocontrolled trials evaluating long-term benefits. Conducting such clinical trials with these two newer antihypertensive agents is currently considered unethical because the benefits of treating uncomplicated hypertension are well established. Since the publication of the JNC VI in 1997, there are now several published clinical trials comparing either ACE inhibitors or calcium channel blockers with first-line antihypertensive agents (diuretics and $\beta$-blockers). ${ }^{9-12}$ These trials have described long-term patient-oriented evidence that matters (POEMs). It is imperative that clinicians be familiar with the major findings of these trials to select evidence-based antihypertensive therapy. The purpose of this review is to determine whether new evidence since the publication of the JNC VI supports the first-line use of ACE inhibitors or calcium channel blockers.

\section{Methods}

A MEDLINE search was performed for January 1993 through August 2000 using the search terms "antihypertensive agents," "hypertension," "ACE inhibitors," "calcium channel blockers," "myocardial infarction," "cardiovascular diseases," "mortality," and "survival." Clinical trials were included if they were human clinical trials that evaluated either ACE inhibitors or calcium channel blockers. Only large-scale clinical trials that evaluated outcomes (eg, cardiovascular events, stroke, mortality, etc) as study endpoints were selected. Clinical trials were excluded if they were not published in English language journals.

Numbers needed to treat (NNT) to prevent one negative outcome were calculated for individual trials and summarized in tabular form. This article will review outcome-based clinical trials that have compared ACE inhibitors and calcium channel blockers with diuretics or $\beta$-blockers in the management of hypertension using the STEP approach: safety (an analysis of adverse effects that patients and providers care about), tolerability (pooled dropout rates from large clinical trials), effectiveness (how well the agent works and in what patient population[s]), and price (cost of drugs, but also cost of effectiveness of therapy). Data from a recent meta-analysis were included to evaluate these findings further.

\section{Safety and Tolerability}

ACE inhibitors and calcium channel blockers are considered safe and well tolerated when used to treat hypertension. The most frequently encountered side effects with ACE inhibitors include a dry cough and hyperkalemia. With calcium channel blockers, constipation, edema, headache, palpitations, and slowing of the heart rate (with agents other than dihydropyridine) can occur.

The Veterans Affairs Cooperative Study Group on Antihypertensive Agents evaluated single-drug therapy for hypertension for 1 year. ${ }^{13}$ The rates of adverse effects leading to termination of treatment were $4.8 \%$ and $6.5 \%$ with captopril and diltiazem, respectively, and $2.2 \%$ and $1.1 \%$ with atenolol and hydrochlorothiazide, respectively (placebo rate was $6.4 \%$ ). Although there were no statistically significant differences in adverse effects between treatments, the modest sample size $(n=176-188$ in each group) could have resulted in a lack of power to detect a difference. These findings are consistent with the quality-of-life evaluations from the Treatment of Mild Hypertension Study (TOMHS), 
Table 1. Blood Pressure Lowering in Large-scale Clinical Trials Comparing Newer with Older Antihypertensive Agents.

\begin{tabular}{|c|c|c|c|c|c|}
\hline Clinical Trial & Treatment Groups & $\begin{array}{l}\text { Mean Baseline } \\
\text { BP (mm Hg) }\end{array}$ & $\begin{array}{l}\text { Mean BP } \\
\text { Reduction } \\
(\mathrm{mm} \mathrm{Hg})\end{array}$ & $\begin{array}{c}\text { Persistence } \\
\text { (\% on Randomized } \\
\text { Drug at End } \\
\text { of Study) }\end{array}$ & $\begin{array}{c}\text { Tolerability } \\
\text { (\% Withdrawn } \\
\text { Because of } \\
\text { Adverse Effects) }\end{array}$ \\
\hline CAPPP $^{9,15}$ & $\begin{array}{l}\text { Captopril }(\mathrm{n}=5,492) \\
\text { Diuretics } / \beta \text {-blockers }(\mathrm{n}=5,493)\end{array}$ & $\begin{array}{l}161.8 / 99.8 \\
159.6 / 98.1\end{array}$ & $11 / 8^{*}$ & Not reported & Not reported \\
\hline STOP-2 $2^{10}$ & $\begin{array}{l}\text { Felodipine/Isradipine }(\mathrm{n}=2,196) \\
\text { Enalapril/Lisinopril }(\mathrm{n}=2,205) \\
\text { Diuretics/ } \beta \text {-blockers }(\mathrm{n}=2,213)\end{array}$ & $194 / 98^{*}$ & $\begin{array}{l}34.5 / 17.5^{*} \\
34.5 / 16.2^{*} \\
34.8 / 16.6^{*}\end{array}$ & $\begin{array}{l}66.2 \\
61.3 \\
62.3\end{array}$ & $\begin{array}{l}\text { Not reported } \\
\text { Not reported } \\
\text { Not reported }\end{array}$ \\
\hline INSIGHT $^{11}$ & $\begin{array}{l}\text { Nifedipine }(\mathrm{n}=3,157) \\
\text { Hydrochlorothiazide/amiloride }(\mathrm{n}=3,164)\end{array}$ & $173 / 99^{*}$ & $35 / 17^{*}$ & $\begin{array}{l}69.0 \\
72.0\end{array}$ & $\begin{array}{l}23.0 \\
16.4\end{array}$ \\
\hline NORDIL $^{12}$ & $\begin{array}{l}\text { Diltiazem }(\mathrm{n}=5,410) \\
\text { Diuretics } / \beta \text {-blockers }(\mathrm{n}=5,471)\end{array}$ & $\begin{array}{l}173.5 / 105.8 \\
173.4 / 105.7\end{array}$ & $\begin{array}{l}20.3 / 18.7^{\dagger} \\
23.3 / 18.7^{\dagger}\end{array}$ & $\begin{array}{l}77.0 \\
93.0\end{array}$ & $\begin{array}{l}\text { Not reported } \\
\text { Not reported }\end{array}$ \\
\hline
\end{tabular}

$\mathrm{BP}=$ blood pressure.

*No difference between groups $(P>.05)$.

${ }^{\dagger}$ Difference between groups in systolic reduction $(P<.001)$.

which compared acebutolol, amlodipine, chlorthalidone, doxazosin, enalapril, and placebo. ${ }^{14}$ After 4 years of treatment, global measures of quality of life were improved similarly with all five antihypertensive treatments. The greatest increases, although not statistically significant, were with acebutolol and chlorthalidone.

The Swedish Trial of Old Patients with Hypertension-2 (STOP-2) study prospectively compared three treatments: ACE inhibitors, calcium channel blockers (long-acting dihydropyridines), and conventional drugs (diuretics and $\beta$-blockers). ${ }^{10}$ This trial design allowed for the addition or replacement of another agent if blood pressure was not optimally reduced or if side effects occurred. No patient was lost to follow-up or refused to continue the study. The percentages of patients who remained on their initially randomized treatment at the time of the last study visit were similar for those taking ACE inhibitors, calcium channel blockers, and conventional drugs $(61.3 \%, 66.2 \%$, and $62.3 \%$, respectively). This finding suggests that long-term tolerability between these agents is similar.

Evaluating tolerability in large-scale clinical trials is difficult when additional drug therapies are permitted. Two indirect markers that can be used are drug therapy persistence (percentage of patients on their originally randomized drug at the end of study) and dropout rates because of adverse effects. These markers in the large-scale clinical trials evaluating ACE inhibitors and calcium channel blockers compared with diuretics and $\beta$-blockers are summarized in Table 1 along with antihypertensive efficacy values. Overall, persistence appears somewhat similar among all agents.

\section{Effectiveness}

Since the publication of the JNC VI, ACE inhibitors and calcium channel blockers have been compared in prospective, outcome-based clinical trials with diuretics and $\beta$-blockers. ${ }^{9-12}$ Antihypertensive medication efficacy is difficult to compare between studies because of the differences in baseline blood pressure values. Within these studies, however, blood pressure reduction (except with diltiazem) appears to be similar when comparing older with newer drugs (Table 1). These studies have described POEMs. The effects of these agents on myocardial infarction (fatal and nonfatal), stroke, cardiovascular events, and total mortality are discussed below and are summarized in Table 2 (ACE inhibitors compared with diuretics and $\beta$-blockers) and Table 3 (calcium channel blockers compared with diuretics and $\beta$-blockers).

The Captopril Prevention Project (CAPPP) was designed to compare the effects of captopril with conventional treatment (diuretics, $\beta$-blockers) on cardiovascular morbidity and mortality in hypertensive patients. ${ }^{9}$ In this prospective, randomized, intention-to-treat, open-label trial with blinded endpoint evaluation, 10,985 patients in Sweden and Finland, aged 25 to 66 years with a diastolic blood pressure of $100 \mathrm{~mm} \mathrm{Hg}$ or more on two occasions, were randomly assigned to captopril or conventional antihypertensive drugs (hydrochlorothiazide, bendrofluazide, metoprolol, or atenolol). The pri- 
Table 2. Clinical Trials Evaluating Angiotensin-Converting Enzyme Inhibitors Compared with Diuretic or $\beta$-Blocker.

\begin{tabular}{|c|c|c|}
\hline Study Endpoints & $\begin{array}{c}\text { CAPPP }^{9} \\
\text { RR }(95 \% \mathrm{CI})^{*}\end{array}$ & $\begin{array}{c}\text { STOP-2 } 2^{10} \\
\text { RR }(95 \% \text { CI)* }\end{array}$ \\
\hline \multicolumn{3}{|l|}{ Combined primary endpoint } \\
\hline $\begin{array}{l}\text { Fatal and nonfatal myocardial infarction } \\
\text { and stroke, or other cardiovascular } \\
\text { deaths }\end{array}$ & $1.05(0.90-1.22)$ & \\
\hline $\begin{array}{l}\text { Fatal myocardial infarction, fatal stroke, } \\
\text { or other fatal cardiovascular disease }\end{array}$ & & $1.01(0.84-1.22)$ \\
\hline \multicolumn{3}{|l|}{ Other endpoints } \\
\hline Fatal and nonfatal myocardial infarction & $0.96(0.77-1.19)$ & $0.90(0.72-1.13)$ \\
\hline Fatal and nonfatal stroke & $1.25^{\dagger}(1.01-1.55)$ & $0.90(0.74-1.08)$ \\
\hline All major cardiovascular events & $0.94(0.83-1.06)$ & $0.94(0.82-1.07)$ \\
\hline Cardiovascular mortality & $0.77(0.57-1.04)$ & $1.01(0.84-1.22)$ \\
\hline Total morbidity & $0.93(0.76-1.14)$ & $1.02(0.89-1.18)$ \\
\hline
\end{tabular}

$\mathrm{RR}=$ relative risk, $\mathrm{CI}=$ confidence interval.

*Angiotensin-converting enzyme inhibitor compared with diuretic or $\beta$-blocker.

${ }^{\dagger} P=.044$.

mary endpoint was fatal and nonfatal myocardial infarction, stroke, and other cardiovascular deaths.

After a mean follow-up of 6.1 years, there was no statistically significant difference in primary endpoint between the captopril and conventional treat- ment groups $(\mathrm{RR}$ [relative risk] $=1.05[0.90-1.22]$ $P=.52)$. Cardiovascular mortality was lower with captopril than with conventional treatment (76 vs 95 events; RR $=0.77$ [0.57-1.04], $P=.092)$; however, this difference failed to reach statistical sig-

Table 3. Clinical Trials Evaluating Calcium Channel Blockers Compared with Diuretic or $\beta$-Blocker.

\begin{tabular}{|c|c|c|c|}
\hline Study Endpoints & $\begin{array}{c}\text { STOP-2 } 2^{10} \\
\text { RR }(95 \% \mathrm{CI})^{*}\end{array}$ & $\begin{array}{l}\text { INSIGHT }^{11} \\
\text { RR }(95 \% \mathrm{CI})^{*}\end{array}$ & $\begin{array}{l}\text { NORDIL }^{12} \\
\text { RR }(95 \% \mathrm{CI})^{*}\end{array}$ \\
\hline \multicolumn{4}{|l|}{ Combined primary endpoint } \\
\hline $\begin{array}{l}\text { Fatal myocardial infarction, fatal } \\
\text { stroke, or other fatal } \\
\text { cardiovascular disease }\end{array}$ & $0.97(0.80-1.17)$ & & \\
\hline $\begin{array}{l}\text { Death from any cardiovascular or } \\
\text { cerebrovascular cause; or } \\
\text { nonfatal myocardial infarction, } \\
\text { stroke, or heart failure }\end{array}$ & & $1.10(0.91-1.34)$ & \\
\hline $\begin{array}{l}\text { Fatal and nonfatal stroke, fatal and } \\
\text { nonfatal stroke myocardial } \\
\text { infarction, or other } \\
\text { cardiovascular death }\end{array}$ & & & $1.00(0.87-1.15)$ \\
\hline \multicolumn{4}{|l|}{ Other endpoints } \\
\hline Myocardial infarction & $\begin{array}{l}\text { Fatal and nonfatal: } 1.18 \\
\quad(0.95-1.47)\end{array}$ & $\begin{array}{l}\text { Fatal: } 3.22^{\dagger}(1.18-8.80) \\
\text { Nonfatal: } 1.09(0.76-1.58)\end{array}$ & $\begin{array}{l}\text { Fatal: } 1.10(0.64-1.88) \\
\text { Fatal and nonfatal: } 1.16 \\
\quad(0.94-1.44)\end{array}$ \\
\hline Stroke & $\begin{array}{l}\text { Fatal and nonfatal: } 0.88 \\
\quad(0.73-1.06)\end{array}$ & $\begin{array}{l}\text { Fatal: } 1.09(0.48-2.48) \\
\text { Nonfatal: } 0.87(0.61-1.26)\end{array}$ & $\begin{array}{l}\text { Fatal: } 0.96(0.52-1.74) \\
\text { Fatal and nonfatal: } 0.8 \\
\quad(0.65-0.99)\end{array}$ \\
\hline All major cardiovascular events & $0.99(0.87-1.12)$ & $1.11(0.90-1.36)$ & $1.04(0.91-1.18)$ \\
\hline Cardiovascular mortality & $0.97(0.80-1.17)$ & $1.16(0.80-1.69)$ & $1.11(0.87-1.43)$ \\
\hline Total mortality & $0.99(0.86-1.15)$ & $1.01(0.80-1.27)$ & $1.00(0.83-1.20)$ \\
\hline
\end{tabular}

$\mathrm{RR}=$ relative risk, $\mathrm{CI}=$ confidence interval.

${ }^{*}$ Calcium channel blocker compared with diuretic or $\beta$-blocker.

${ }^{\dagger} P=.017$. 
nificance. Although the rates of fatal and nonfatal myocardial infarction were similar (162 vs 161), fatal and nonfatal stroke was more common with captopril (189 vs 148 ; RR $=1.25$ [1.01-1.55], number needed to harm $[\mathrm{NNH}]=133, P=.044)$. The authors attribute this small increase in stroke to higher baseline systolic and diastolic blood pressures in patients in the captopril group compared with the conventional group. A potential confounder of this study was that the addition of a diuretic was allowed, if needed, in those randomized to captopril.

The efficacy of newer antihypertensive medications (ACE inhibitors, calcium channel blockers) compared with conventional agents (diuretic, $\beta$-blockers) was also assessed in the STOP-2 study. ${ }^{10}$ In this prospective, randomized, open-label, blinded-endpoint, intention-to-treat trial, patients aged 70 to 84 years with hypertension (blood pressure $\geq 180 \mathrm{~mm} \mathrm{Hg}$ systolic, $\geq 105 \mathrm{~mm} \mathrm{Hg}$ diastolic, or both) were randomly assigned conventional antihypertensive drugs (atenolol $50 \mathrm{mg}$, metoprolol $100 \mathrm{mg}$, pindolol $5 \mathrm{mg}$, or hydrochlorothiazide $25 \mathrm{mg}$ plus amiloride $2.5 \mathrm{mg}$, daily) or newer drugs (enalapril $10 \mathrm{mg}$, lisinopril $10 \mathrm{mg}$, felodipine $2.5 \mathrm{mg}$, or isradipine $2.5 \mathrm{mg}$, daily). Of the 6,614 patients randomly assigned to treatment, 2,213 received conventional drugs, 2,205 received an ACE inhibitor, and 2,196 received calcium channel blockers. The primary endpoint was a combined endpoint of fatal myocardial infarction, fatal stroke, or other fatal cardiovascular disease.

Among patients, blood pressure was reduced similarly in all treatment groups $(34.8 / 16.6 \mathrm{~mm} \mathrm{Hg}$ in the conventional group, $34.5 / 16.2 \mathrm{~mm} \mathrm{Hg}$ in the ACE-inhibitor group, and $34.5 / 17.5 \mathrm{~mm} \mathrm{Hg}$ in the calcium channel blocker group). There was no difference in the combined primary endpoint between the conventional drugs (both ACE-inhibitor and calcium channel blocker groups) and newer drugs $(\mathrm{RR}=0.99[0.84-1.16] ; P=.89)$. Additionally, when comparing ACE inhibitors and calcium channel blockers separately with conventional drugs, no differences in primary endpoint, cardiovascular mortality, all myocardial infarction, all stroke, all major cardiovascular events, or total mortality were noted. Similar to the CAPPP trial, a potential confounder was allowing the addition of either a diuretic (in the ACE-inhibitor group) or $\beta$-blocker (in the calcium channel blocker group) in patients who required additional blood pressure lowering.
Two studies have recently been published comparing calcium channel blockers with conventional treatment. The INSIGHT trial compared the effects of long-acting nifedipine with the combination diuretic co-amilozide (hydrochlorothiazide 25 $\mathrm{mg}$, amiloride $2.5 \mathrm{mg}$ ) on cardiovascular morbidity and mortality in high-risk patients with hypertension. ${ }^{11}$ In this prospective, randomized, doubleblinded trial in Europe and Israel, 6,321 patients aged 55 to 80 years with hypertension $(\geq 150 / 95$ $\mathrm{mm} \mathrm{Hg}$ or $\geq 160 \mathrm{~mm} \mathrm{Hg}$ systolic) received either nifedipine $30 \mathrm{mg}$ in a long-acting gastrointestinal transport system formulation $(\mathrm{n}=3,157)$ or coamilozide (hydrochlorothiazide $25 \mathrm{mg}$ and amiloride $2.5 \mathrm{mg})(\mathrm{n}=3,164)$. In patients whose blood pressure decreased by less than $20 / 10 \mathrm{~mm} \mathrm{Hg}$ or was higher than $140 / 90 \mathrm{~mm} \mathrm{Hg}$, the study drug dose was doubled. Atenolol (or enalapril if atenolol was contraindicated) was added, if needed. The primary outcome was composite death from any cardiovascular or cerebrovascular cause, together with nonfatal myocardial infarction, stroke, or heart failure.

After an average of 3.5 years, primary outcomes occurred in $200(6.3 \%)$ patients in the nifedipine group and in $182(5.8 \%)$ in the co-amilozide group $(\mathrm{RR}=1.10$ [0.91-.34], $P=.35)$. There were no differences in nonfatal myocardial infarction, sudden death, fatal or nonfatal stroke, heart failure, or other cardiovascular deaths $(P>.05$ for all). Nifedipine, however, was associated with a greater risk of fatal myocardial infarction compared with conventional therapy $(\mathrm{RR}=3.22[1.18-8.80], P=$ .014). While statistically significant, fatal myocardial infarction was considered a secondary endpoint of this study. The absolute risk increase (ARI) was small because of the infrequent nature of this event $(\mathrm{ARI}=0.3 \%, \mathrm{NNH}=333)$. Patients were not allowed to receive a drug from the other group during their titration phases. However, both groups allowed atenolol or enalapril as add-on therapy. The need for add-on therapy in each group was not reported, which potentially could have skewed results if the use of $\beta$-blockers (known to reduce the risk of myocardial infarction) was unequal between the two groups.

The second study that assessed the efficacy of calcium channel blockers in decreasing cardiovascular morbidity and mortality compared diltiazem (not a dihydropyridine) with diuretics and $\beta$ blockers. ${ }^{12}$ In this prospective, randomized, open, 
blinded endpoint study, 10,881 patients aged 50 to 74 years in Norway and Sweden, who had a diastolic blood pressure of $100 \mathrm{mg} \mathrm{Hg}$ or more on two occasions, were randomized to receive either diltiazem or diuretics, $\beta$-blockers, or both. The combined primary endpoint was fatal and nonfatal stroke, myocardial infarction, or other cardiovascular death.

After a mean follow-up of 4.5 years and 48,992 patient-years accumulated, systolic and diastolic blood pressures were lowered effectively in both the diltiazem and diuretic and $\beta$-blocker groups (reduction 20.3/18.7 vs 23.3/18.7 mm Hg; difference in systolic reduction $P<.001)$. A primary endpoint occurred in 403 patients in the diltiazem group and in 400 in the diuretic and $\beta$-blocker group (16.6 vs 16.2 per 1,000 patient-years, $\mathrm{RR}=$ $1.00[0.87-1.15], P=.97)$. Interestingly, fatal and nonfatal stroke occurred less frequently in the diltiazem group than in the diuretic and $\beta$-blocker group $(\mathrm{RR}=0.80$ [0.65-0.99], NNT $=154 ; P=$ $.04)$. There were no differences in myocardial infarction, cardiovascular death, or total mortality $(P>.05$ for all $)$.

\section{Price}

Cost of antihypertensive therapy can vary greatly from patient to patient. Not only are drug costs highly variable depending on the class chosen and the availability of generics, but also most patients will require more than one drug to achieve blood pressure control. ${ }^{16}$ Table 4 lists the average monthly medication cost for several frequently prescribed antihypertensive agents. Three generic ACE inhibitors are now available (captopril, enalapril, and lisinopril), which has reduced considerably the cost of this drug class. Several long-acting calcium channel blockers are branded products and incur the highest costs.

Other factors that should be considered when evaluating cost-effectiveness of antihypertensive drugs include the need for laboratory monitoring and office visits. Switches between classes because of therapeutic failures should also be considered, but studies have shown that the need to switch $\beta$-blockers and diuretics for this reason is small and similar to that of newer antihypertensive drugs. ${ }^{13,14}$ In an economic evaluation of JNC VI guidelines from a randomized controlled trial, diuretics and $\beta$-blockers were the most attractive options. ${ }^{17}$ This analysis, however, did not consider all currently
Table 4. Monthly Cost of Selected Antihypertensive Agents.

\begin{tabular}{llc}
\hline Drug & Usual Dose & $\begin{array}{c}\text { Cost per } \\
\text { Month* } \\
(\$)\end{array}$ \\
\hline Hydrochlorothiazide (generic) & $25 \mathrm{mg} \mathrm{qd}$ & 2.40 \\
Atenolol (generic) & $50 \mathrm{mg} \mathrm{qd}$ & 2.40 \\
Metoprolol tartrate (generic) & $50 \mathrm{mg} \mathrm{bid}$ & 9.56 \\
Captopril (generic) & $25 \mathrm{mg} \mathrm{bid}$ & 8.42 \\
Enalapril maleate (generic) & $10 \mathrm{mg} \mathrm{qd}$ & 17.67 \\
Lisinopril (Prinivil, Zestril) $^{\dagger}$ & $10 \mathrm{mg} \mathrm{qd}$ & 27.94 \\
Nifedipine CR (generic) & $60 \mathrm{mg} \mathrm{qd}$ & 27.25 \\
Diltiazem CD (generic) & $180 \mathrm{mg} \mathrm{qd}$ & 23.42 \\
Verapamil CR tablet (generic) $^{*} 180 \mathrm{mg} \mathrm{qd}$ & 7.00 \\
Amlodipine (Norvasc) & $5 \mathrm{mg} \mathrm{qd}$ & 39.82 \\
\hline
\end{tabular}

Note: qd = every day, bid - twice a day.

*From drugstore.com (available at: http://www.drugstore.com). Calculated based on a 90- to 100-tablet purchase.

${ }^{\dagger}$ Generic lisinopril (Prinivil only) approved, but not yet available.

available generic ACE inhibitors (enalapril and lisinopril). Whereas diuretics might require greater laboratory monitoring, medication costs for these agents are much lower. Additionally, although differences in efficacy and compliance might exist between various antihypertensive drug classes, these differences appear to be small and would have relatively little impact on the overall cost of managing hypertension. ${ }^{17}$

Cost-effectiveness of intensive treatment of hypertension has been reported. Using the Hypertension Optimal Treatment (HOT) trial, which assessed the consequences of three different targets of diastolic blood pressure lowering ( $\leq 90 \mathrm{~mm} \mathrm{Hg}$, $\leq 85 \mathrm{~mm} \mathrm{Hg}$, and $\leq 80 \mathrm{~mm} \mathrm{Hg}$ ), a cost-effectiveness analysis was performed. ${ }^{18}$ The treatment target of $90 \mathrm{~mm} \mathrm{Hg}$ was found to be highly costeffective. The cost-effectiveness ratio, expressed as cost per year of life gained, was $\$ 4,262$ in the $<90$-mm Hg treatment target group and $\$ 12,710$ for the added aspirin treatment group. Treatments to lower blood pressure further to $85 \mathrm{~mm} \mathrm{Hg}$ were marginally cost-effective (cost-effectiveness ratio $=$ $\$ 86,360$ ) and not cost-effective for blood pressure lowering to $80 \mathrm{~mm} \mathrm{Hg}$ (cost-effectiveness ratio = $\$ 658,370)$.

\section{Discussion}

The JNC VI guidelines recommend only diuretics and $\beta$-blockers as first-line therapy for uncomplicated hypertension based on definitive placebo- 
controlled trials. Similar trials with ACE inhibitors and calcium channel blockers will not be conducted because the benefits of antihypertensive treatment are conclusive. In comparison, the 1999 World Health Organization-International Society of Hypertension Guidelines for the Management of Hypertension recommends ACE inhibitors and calcium channel blockers along with diuretics and $\beta$-blockers. ${ }^{19}$ These guidelines, however, state that fewer data are available that support these newer agents. More data are now available with the completion of the trials previously discussed.

The Antihypertensive and Lipid-Lowering Treatment to Prevent Heart Attack Trial (ALLHAT) study is a large-scale, prospective, randomized, double-blind trial in 40,000 high-risk hypertensive patients. It is designed to determine whether the combined incidence of fatal coronary heart disease and nonfatal myocardial infarction differs between persons randomized to a diuretic (chlorthalidone), a calcium channel blocker (amlodipine), an ACE inhibitor (lisinopril), or an $\alpha$-blocker (doxazosin). ${ }^{20}$ Findings from this trial will provide more conclusive answers about comparative effects of ACE inhibitors and calcium channel blockers in hypertension. Although the $\alpha$-blocker arm has been terminated early because of a higher incidence of heart failure, ${ }^{21}$ this study was not yet completed when this review was written.

In the large-scale comparative trials discussed, morbidity and mortality data with newer agents were similar to those with diuretics and $\beta$-blockers. There were no large appreciable differences in primary outcomes with ACE inhibitors and calcium channel blockers. Only one major finding (stroke in the CAPPP trial) was worse with ACE inhibitors. This finding can reasonably be explained by baseline blood pressure differences in the two treatment groups. Data from the Heart Outcomes Prevention Evaluation (HOPE) study indicate that the ACE inhibitor ramipril reduces morbidity and mortality in patients at high risk for cardiovascular disease. ${ }^{22}$ Although the HOPE study did not compare ramipril with other agents, it provides additional evidence showing benefit with ACE-inhibitor therapy. Overall it appears that ACE inhibitors provide benefits to patients with hypertension in a fashion similar to diuretics and $\beta$-blockers.

Clinical trials evaluating calcium channel blockers have mixed results. Although composite primary outcomes were similar, risks of fatal myocar- dial infarction and nonfatal heart failure (both secondary endpoints) were statistically higher with long-acting nifedipine in the INSIGHT trial. Moreover, a recently published meta-analysis of nine clinical trials showed a higher risk of myocardial infarction (odds ratio $[\mathrm{OR}]=1.26, P=.0003$ ), congestive heart failure $(\mathrm{OR}=1.25, P=.005)$, and major cardiovascular events $(\mathrm{OR}=1.10, P=.018)$ with long-acting dihydropyridine calcium channel blockers compared with diuretics and $\beta$-blockers. ${ }^{23}$

The design of the STOP-2 study allows for comparisons between ACE inhibitors and calcium channel blockers. The risk of experiencing the combined primary endpoint was no different with ACE inhibitors than with calcium channel blockers $(\mathrm{RR}=1.04[0.86-1.26], P=.67)$. The secondary endpoints of all myocardial infarction $(\mathrm{RR}=0.77$ [0.61-0.96], $P=.018)$ and frequency of heart failure $(\mathrm{RR}=0.78$ [0.63-0.97], $P=.025)$, however, statistically favored ACE-inhibitor therapy. Other clinical trials in hypertensive patients with diabetes indicate that ACE inhibitors provide greater cardiovascular risk reduction than calcium channel blockers. $^{24,25}$ This finding adds strength to the controversy suggesting that calcium channel blockers might not be as protective as other antihypertensive agents.

There are several pharmacological differences between dihydropyridine calcium channel blockers (potent peripheral vasodilation, and possible reflex tachycardia) and calcium channel blockers other than dihydropyridine (less-potent vasodilation, decreased heart rate). Significant differences in outcomes were not found in the NORDIL trial, which used the diltiazem (not a dihydropyridine). Longterm outcome data with verapamil (the other drug agent that is not a dihydropyridine) in hypertension are not yet available. Data from the Controlled Onset Verapamil Investigation of Cardiovascular Endpoints (CONVINCE) trial, however, will provide useful clinical information with the use of this calcium channel blocker in hypertension. This large-scale prospective clinical trial compared verapamil-based therapy (using a long-acting formulation) with diuretic and $\beta$-blocker based therapy. ${ }^{26}$ It was concluded in early 2001, and data should be available soon.

Despite the recommendations from the JNC VI, the use of $\beta$-blockers and diuretics has dropped, while the use of calcium channel blockers and ACE inhibitors has increased. In one study, calcium 
channel blockers represented $38 \%$ of prescriptions for antihypertensive agents, whereas $\beta$-blockers and diuretics accounted for only $11 \%$ and $8 \%$, respectively. ${ }^{27}$ One reason could be the massive and overt marketing campaigns of pharmaceutical companies. Numerous studies have detailed the impact of pharmaceutical marketing on physician prescribing patterns. ${ }^{28-30}$ One particular study found that $40 \%$ of primary care physicians incorrectly reported that calcium channel blockers were 50\% more likely to achieve normal blood pressure than thiazide diuretics and reduce the risk of stroke. ${ }^{31}$ Calcium channel blockers are among the most heavily marketed and most commonly detailed drugs. It is important and reasonable for physicians to demand evidence to support claims of drug superiority before changing prescribing patterns. This review of newer literature and the current JNC VI guidelines serve as excellent resources for physicians treating patients with hypertension.

\section{Conclusion}

The JNC VI recommends diuretics and $\beta$-blockers as first-line therapy for uncomplicated hypertension. Recently published outcomes data should be considered in the context of these recommendations. Based on these findings, it is reasonable to consider ACE inhibitors as possible first-line therapy for hypertension. Cardiovascular outcomes are similar to those found with diuretics and $\beta$-blockers, and lower cost generic products are now available. Calcium channel blockers should be reserved as second-line agents for patients with uncomplicated hypertension. Clinical trials and meta-analyses data suggest that these agents might not reduce cardiovascular risk as well as first-line antihypertensive agents, including ACE inhibitors, and these agents are more costly.

\section{References}

1. The sixth report of Joint National Committee on Prevention, Detection, Evaluation, and Treatment of High Blood Pressure. Arch Intern Med 1997;157: 2413-46.

2. 1999 Heart and stroke statistical update. Dallas: American Heart Association, 1998.

3. The fifth report of the Joint National Committee on Detection, Evaluation, and Treatment of High Blood Pressure (JNC V). Arch Intern Med 1993;153: 154-83.

4. Prevention of stroke by antihypertensive drug treatment in older persons with isolated systolic hyper- tension. Final results of the Systolic Hypertension in the Elderly Program (SHEP). SHEP Cooperative Research Group. JAMA 1991;265:3255-64.

5. Dahlöf B, Lindholm LH, Hansson L, Schersten B, Ekbom T, Wester PO. Morbidity and mortality in the Swedish Trial in Old Patients with Hypertension (STOP-Hypertension). Lancet 1991;338:1281-85.

6. Medical Research Council trial of treatment of hypertension in older adults: principal results. MRC Working Party. BMJ 1992;304:405-12.

7. Nelson CR, Knapp DA. Trends in antihypertensive drug therapy of ambulatory patients by US officebased physicians. Hypertension 2000;36:600-3.

8. Knight EL, Glynn RJ, Levin R, Ganz DA, Avorn J. Failure of evidence-based medicine in the treatment of hypertension in older patients. J Gen Intern Med 2000;15:702-9.

9. Hansson L, Lindholm LH, Niskanen L, et al. Effect of angiotensin-converting-enzyme inhibition compared with conventional therapy on cardiovascular morbidity and mortality in hypertension: the Captopril Prevention Project (CAPPP) randomised trial. Lancet 1999;353:611-6.

10. Hansson L, Lindholm LH, Ekbom T, et al. Randomized trial of old and new antihypertensive drugs in elderly patients: cardiovascular mortality and morbidity the Swedish Trial in Old Patients with Hypertension-2 Study. Lancet 1999;354:1751-6.

11. Brown MJ, Palmer CR, Castaigne A, et al. Morbidity and mortality in patients randomized to doubleblind treatment with a long-acting calcium-channel blocker or diuretic in the International Nifedipine GITS study: Intervention as a Goal in Hypertension Treatment (INSIGHT). Lancet 2000;356:366-72.

12. Hansson L, Hedner T, Lund-Johansen P, et al. Randomized trial of effects of calcium antagonists compared with diuretics and beta-blockers on cardiovascular morbidity and mortality in hypertension: the Nordic Diltiazem (NORDIL) study. Lancet 2000; 356:359-65.

13. Materson BJ, Reda DJ, Cushman WC, et al. Singledrug therapy for hypertension in men. A comparison of six antihypertensive agents with placebo. The Department of Veterans Affairs Cooperative Study Group on Antihypertensive Agents. N Engl J Med 1993;328:914-21.

14. Grimm RH Jr, Grandits GA, Cutler JA, et al. Relationships of quality-of-life measures to long-term lifestyle and drug treatment in the Treatment of Mild Hypertension Study. Arch Intern Med 1997; 157:638-48.

15. Hansson L, Hedner T, Lindholm L, et al. The Captopril Prevention Project (CAPPP) in hypertension-baseline data and current status. Blood Press 1997;6:365-7.

16. Hansson L, Zanchetti A, Carruthers SG, et al. Effects of intensive blood-pressure lowering and lowdose aspirin in patients with hypertension: principal 
results of the Hypertension Optimal Treatment (HOT) randomised trial. HOT Study Group. Lancet 1998;351:1755-62.

17. Ramsey SD, Neil N, Sullivan SD, Perfetto E. An economic evaluation of the JNC hypertension guidelines using data from a randomized controlled trial. Joint National Committee. J Am Board Fam Pract 1999;12:105-14.

18. Cost effectiveness of intensive treatment of hypertension. Am J Manag Care 1998;4(12 Suppl): S765-69.

19. 1999 World Health Organization-International Society of Hypertension Guidelines for the Management of Hypertension. Guidelines Subcommittee J Hypertens 1999;17:151-83.

20. Davis BR, Cutler JA, Gordon DJ, et al. Rationale and design for the Antihypertensive and Lipid Lowering Treatment to Prevent Heart Attack Trial (ALLHAT). ALLHAT Research Group. Am J Hypertens 1996;9(4 Pt 1):342-60.

21. Major cardiovascular events in hypertensive patients randomized to doxazosin vs chlorthalidone. The Antihypertensive and Lipid-Lowering Treatment to Prevent Heart Attack Trial (ALLHAT). ALLHAT Collaborative Research Group. JAMA 2000;283: 1967-75.

22. Yusuf S, Sleight P, Pogue J, Bosch J, Davies R, Dagenais G. Effects of an angiotensin-convertingenzyme inhibitor, ramipril, on cardiovascular events in high-risk patients. The Heart Outcomes Prevention Evaluation Study Investigators. N Engl J Med 2000;342:145-53.

23. Pahor M, Psaty BM, Alderman MH, et al. Health outcomes associated with calcium antagonists compared with other first-line antihypertensive therapies: a meta-analysis of randomised controlled trials. Lancet 2000;356:1949-54.

24. Tatti P, Pahor M, Byington RP, et al. Outcome results of the Fosinopril Versus Amlodipine Cardiovascular Events Randomized Trial (FACET) in patients with hypertension and NIDDM. Diabetes Care 1998;21:597-603.

25. Estacio RO, Jeffers BW, Hiatt WR, Biggerstaff SL, Gifford N, Schrier RW. The effect of nisoldipine as compared with enalapril on cardiovascular outcomes in patients with non-insulindependent diabetes and hypertension. N Engl J Med 1998;338:645-52.

26. Black HR, Elliott WJ, Neaton JD, et al. Rationale and design for the Controlled ONset Verapamil INvestigation of Cardiovascular Endpoints (CONVINCE) trial. Control Clin Trials 1998;19: 370-90.

27. Siegal D, Lopez J. Trends in antihypertensive drug use in the United States - do the JNC V recommendations affect prescribing? Fifth Joint National Committee on the Detection, Evaluation, and Treatment of High Blood Pressure. JAMA 1997;278: 1745-8

28. Orlowski JP, Wateska L. The effects of pharmaceutical firm enticements on physician prescribing patterns. There is no such thing as a free lunch. Chest 1992;102:270-3.

29. Chew LD, O'Young TS, Hazlet TK, Bradley KA, Maynard C, Lessler DS. A physician survey of the effect of drug sample availability on physicians' behavior. J Gen Intern Med 2000;15:478-83.

30. Chren MM, Landefeld CS. Physicians' behavior and their interactions with drug companies. A controlled study of physicians who requested additions to a hospital drug formulary. JAMA 1994;271:684-9.

31. Ubel PA, Adler MA. Primary care physicians believe that calcium blockers and ACE inhibitors are superior to beta-blockers and diuretics in treating uncomplicated hypertension. J Gen Intern Med 1999; 14(Suppl 2):125. 